\title{
Identificação de Altas Habilidades em artigos publicados na Revista Educação Especial
}

\author{
High Abilities Identification on papers published at the Special Education \\ Journal
}

Identificación de Altas Habilidades en artículos publicados en la Revista Educación Especial

\author{
Josilene Domingues Santos Pereira \\ Professora do Instituto Federal da Bahia, Vitória da Conquista, Bahia, Brasil. \\ josidomingues.ifba@gmail.com \\ ORCID - https://orcid.org/0000-0001-5392-9006
}

\section{Fabiana Oliveira Koga}

Doutora pela Universidade Estadual Paulista Júlio de Mesquita Filho, Marília, São Paulo, Brasil. fabianapsicopedagogiamusical@gmail.com

ORCID - https://orcid.org/0000-0002-4646-1537

Rosemeire de Araújo Rangni

Professora doutora na Universidade Federal de São Carlos, São Carlos, São Paulo, Brasil.

rose.rangni@uol.com.br

ORCID - http://orcid.org/0000-0002-8752-9745

Recebido em 29 de agosto2019

Aprovado em 27 de junho de 2020

Publicado em 8 de julho de 2020

\section{RESUMO}

A identificação de pessoas com altas habilidades (PAH), embora seja uma temática amplamente discutida no meio acadêmico, tem sido caracterizada como um processo complexo e desafiador, especialmente no contexto escolar, devido à escassez de instrumentos validados e ao despreparo de educadores no que se refere à identificação e ao atendimento as PAH. Os objetivos deste estudo foram: (i) caracterizar a produção científica sobre altas habilidades(AH) na Revista Educação Especial da Universidade Federal de Santa Maria - Brasil, em relação à distribuição temporal, ao tipo de produção científica, à autoria, à vinculação institucional e às temáticas; (ii) analisar as pesquisas empíricas sobre a identificação de $\mathrm{PAH}$, em relação ao método, aos procedimentos, instrumentos e resultados alcançados. Para tanto, realizou-se uma pesquisa bibliográfica. Os artigos, publicados no período de 2000 a 2018, foram submetidos a uma análise qualiquantitativa. Os resultados demonstraram que há uma produção exígua (56) sobre as $\mathrm{AH}$ no periódico, sendo doze (12) artigos sobre a temática da identificação de PAH. Desse total, apenas oito $(n=8)$ foram estudos empíricos. Além disso, constatou-se, principalmente, que houve: (i) aumento no número de artigos publicados sobre $\mathrm{AH}$, variando em ascendências e declínios durante o período pesquisado; (ii) maior índice de publicações sobre alguns temas; (iii) fragilidades metodológicas nos estudos publicados, devido a lacunas na seleção e caracterização dos participantes, na descrição dos instrumentos de coleta e nos procedimentos de análise dos dados. Conclui-se que é 
http://dx.doi.org/10.5902/1984686X39764

necessário realizar mais pesquisas empíricas com/sobre esse público da Educação Especial e desenvolver estudos com mais rigor metodológico.

Palavras-chave: Altas habilidades; Educação Especial; identificação.

\section{ABSTRACT}

The identification of people with high abilities (PHA), although it is a widely discussed theme in the academic environment, has been characterized as a complex and challenging process, especially in the school context, due to the lack of validated instruments and the educators training in what concerns the identification and care of PHA. The objectives of this study were: (i) to characterize the scientific production on High Abilities (HA) in the Special Education Journal of the Federal University of Santa Maria- Brazil, in relation to the temporal distribution, the type of scientific production, the authorship, the institutional linkage, and the themes; (ii) to analyze the empirical researches on PHA identification according to the method, procedures, instruments, and results. For this, a bibliographic research and qualitative and quantitative analysis of the published papers from 2000 to 2018 were performed. The results showed that there is a limited production (56) on $\mathrm{HA}$ at the journal with twelve (12) papers on identification of PHA. Of this total, only eight $(n=8)$ were empirical studies. In addition, it was found, mainly, that there were: (i) increasing in the number of published papers on HA varying in ascendancy and decline during the surveyed period; (ii) higher index of publications in some themes;(iii) methodological weaknesses in studies published due to gaps in the selection and characterization of participants, description of collection and data analysis procedures. It is concluded that it is necessary to conduct more empirical researches with / about this Special Education public and to develop studies with more methodological rigor.

Keywords: High abilities; Special Education; identification.

\section{RESUMEN}

La identificación de personas con altas habilidades (PAH), aunque es un tema ampliamente discutido en el campo académico, se ha caracterizado como un proceso complejo y desafiante, especialmente en el contexto escolar, debido a la falta de instrumentos validados y de preparación de los educadores en lo que se refiere a la identificación y cuidado de la PAH. Los objetivos de este estudio fueron: (i) caracterizar la producción científica en altas habilidades $(\mathrm{AH})$ en la Revista de Educación Especial de la Universidad Federal de Santa María- Brasil, en acuerdo con la distribución temporal, el tipo de producción científica, la autoría, el vínculo institucional y los temas; (ii) analizar la s investigacionesempíricas sobre identificación de PAH a cerca del método, procedimientos, instrumentos y resultados obtenidos. Así, se realizó una investigación bibliográficay un análisis cualitativo y cuantitativo de los artículos publicados entre 2000 y 2018. Los resultados mostraron que hay una producción limitada (56) sobre AH en la revista, siendo doce (12) artículos sobre identificación de PAH. De este total, solo ocho $(n=8)$ fueron estudios empíricos. Además, se encontró, principalmente, que hubo: (i) aumento en el número de artículos publicados sobre $\mathrm{AH}$, que variaron en ascendencia y declive durante el período encuestado; (ii) mayor índice de publicaciones en algunos temas; (iii) debilidades metodológicas en estudios, debido a lagunas en la selección y caracterización de los participantes, la descripción de los instrumentos de recolección y los procedimientos de análisis de datos. Se concluye que es necesario realizar más investigación empírica con / sobre este público de Educación Especial y desarrollar estudios con más rigor metodológico.

Palabras clave: Altas habilidades; Educación Especial; identificación. 
http://dx.doi.org/10.5902/1984686X39764

\section{Introdução}

A identificação de pessoas com altas habilidades (PAH) tem sido caracterizada como um processo complexo e desafiador (MACHADO, STOLTZ, 2016; PISKE, 2016). Essa complexidade, conforme se observa na literatura da área, relaciona-se a algumas questões fundamentais do ponto de vista teórico-filosófico (quais concepções de altas habilidades $(\mathrm{AH})$ e de inteligência estão subjacentes no processo de identificação?), de ordem metodológica (quais procedimentos e instrumentos de identificação utilizar e quais são eficazes e válidos?) e do ponto de vista prático (para que identificar?).

Dentre essas questões, os procedimentos de identificação de PAH têm sido, possivelmente, um dos temas sobre os quais mais se têm discutido na área das $\mathrm{AH}$, principalmente considerando as contribuições de teorias contemporâneas que expõem novas concepçõessobre a inteligência e as $A H$ (BROWN et al., 2005). Teorias mais recentes (TREFFINGER; RENZULLI, 1986; STERNBERG, 2000; RENZULLI, 2005) têm demonstrado a necessidade de se realizar um processo de identificação mais amplo que envolva vários procedimentos, instrumentos e diversas fontes de informação (RENZULLI, 1990; GUENTHER; FREEMAN, 2000).

Desse modo, várias estratégias e modelos de identificação de $\mathrm{PAH}$, desde meados do século XX, vêm sendo produzidos pelos pesquisadores da área (VIRGOLIM, 2016). Sabe-se que os modelos, os procedimentos e os variados instrumentos estão diretamente relacionados às diversas concepções de AH (STERNBERG; DAVIDSON, 2005) e de inteligência (GARDNER; 1994; 2001; STERNBERG, 2000) que foram, ao longo do tempo, produzidas e propostas pelos estudiosos da temática.

Vários pesquisadores (RENZULLI, 2005; ALENCAR, 1986; GAMA, 2006; VIRGOLIM, 2016), além disso, ressaltam também que a identificação de PAH deve estar comprometida com o atendimento especializado de suas necessidades e capacidades superiores, com a individualização de sua educação e não com a rotulação do indivíduo, o que representaria, de fato, um desserviço, uma vez que a criação de expectativas em torno do rótulo, sem as devidas propostas de atendimento, culminariam improdutivas tanto no âmbito individual, familiar quanto social.

Nesse sentido, alguns documentos que legislam sobre a Educação Especial (EE) no Brasil (BRASIL, 2008, 2011), ao reconhecerem os estudantes com AH como público-alvo da EE, estabelecem, por sua vez, diretrizes para o atendimento educacional especializado em razão de suas características cognitivas, emocionais e sociais. Para tanto, os 
http://dx.doi.org/10.5902/1984686X39764

procedimentos de identificação de $\mathrm{AH}$ devem ser considerados nas práticas escolares. Virgolim (2016) argumenta que, embora a identificação desses grupos no contexto escolar, ao longo do tempo, tenha assumido um caráter hesitante e incompleto, práticas para identificação desse público foram propostas pelas políticas públicas brasileiras.

No âmbito das políticas, verifica-se ainda que a plena efetivação das práticas depende diretamente da formação e da capacitação de professores e da equipe pedagógica da escola. Por essa razão, um dos objetivos dos Núcleos de Altas Habilidades/Superdotação (NAAH/S) consiste em formar professores e profissionais da educação para a identificação e, consequentemente, o atendimento aos estudantes com AH (BRASIL, 2006).

Vigoram ainda, apesar disso, práticas de identificação que continuam baseando-se unicamente em medidas de testes de habilidades cognitivas (BROWN et al., 2005). Os testes tradicionais de inteligência, como se tornou uma questão consensual entre os pesquisadores da área, além de representar uma amostra muito limitada e insuficiente do que se sabe hoje sobre a inteligência humana (ALENCAR, 1986), podem ser altamente excludentes, pois seu conteúdo reflete conhecimentos (re)produzidos com mais frequência por classes socioeconômicas mais favorecidas (ALENCAR, FLEITH, 2001).

O Brasil ainda reproduz fortemente a tradição dos testes psicométricos os quais, por sua vez, estão atrelados à reprodução de definições unidimensionais de inteligência e superdotação, corroborando, no contexto escolar, para as práticas de identificação por meio de laudos psicológicos como indicadores de AH (VIRGOLIM, 2016), contrariando a Nota Técnica 04/2014 (BRASIL, 2014), a qual caracteriza como desnecessária a exigência de laudos médicos para o Atendimento Educacional Especializado (AEE), principalmente porque esse tipo de atendimento tem caráter pedagógico e não clínico. Além disso, a exigência de laudos reforça ainda a configuração de barreiras, impedindo o acesso à escolarização dos estudantes e denotando uma exclusão de seus direitos (BRASIL, 2014).

Salienta-se, entretanto, de um modo geral, que os testes podem imprimir certa facilidade de manejo pela sua usabilidade, possibilidade de aplicação em massa e facilidade na tabulação de seus resultados. Além disso, a aplicação de testes psicométricos fornece respostas rápidas e objetivas sobre os resultados e, por serem validados e fidedignos, em sua maioria, induzem certa margem de segurança com relação a seus resultados, considerando especialmente o fato de que a aprovação e aplicação de testes psicológicos são regidas e fiscalizadas pelo Conselho de Psicologia no Brasil. (PASQUALI, 2013; LINS; BORSA, 2017). Esses aspectos podem representar um dos principais motivos 
http://dx.doi.org/10.5902/1984686X39764

de práticas escolares ainda exigirem laudos de $\mathrm{AH}$ aos estudantes matriculados nas redes regulares de ensino em todo o Brasil.

Nota-se, desse modo, uma situação paradoxal no que diz respeito ao trabalho de identificação de PAH no Brasil: por um lado, as orientações em documentos oficiais que regem a EE salientam e reforçam a tese de que essa identificação deve ser feita no âmbito pedagógico, visando ao atendimento educacional desse público; por outro lado, as práticas escolares ainda perpetuam a exigência de laudos médicos a fim de que seja fornecido tal atendimento.

Por essa razão, torna-se necessário investigar, no âmbito da produção científica brasileira, quais os procedimentos e instrumentos de identificação têm sido utilizados nas pesquisas sobre a identificação das AH. Assim, objetiva-se, por meio deste estudo, em um primeiro momento, caracterizar a produção científica sobre AH na Revista Educação Especial (REE) da Universidade Federal de Santa Maria, no período de 2000 a 2018, com base nos seguintes indicadores bibliométricos: distribuição temporal, tipo de produção científica, autoria, vinculação institucional dos autores e temáticas. Em um segundo momento, analisar os artigos empíricos sobre a identificação, no que se refere ao método, aos procedimentos, aos instrumentos utilizados para identificação das $\mathrm{AH}$ e aos resultados alcançados.

O recorte temporal compreende dezenove anos $(n=19)$ de publicações da REE. Esse recorte de tempo, entre 2000 e 2018, foi selecionado, considerando todo armazenamento das edições disponíveis no site da Revista, no período do levantamento bibliográfico, ocorrido em dezembro de 2018.

A escolha por esse periódico, que teve sua criação em $1987^{1}$, deve-se, principalmente, à publicação de pesquisas voltadas exclusivamente para os temas da EE. Além disso, a REE constitui, no cenário brasileiro, um repositório fundamental da história sobre a pesquisa na área da Educação Especial, sendo, na atualidade, classificada com Qualis A2 pela Coordenação de Aperfeiçoamento de Pessoal de Nível Superior (CAPES), índice que é usado para classificar a produção científica dos Programas de Pós-Graduação, especialmente dos artigos publicados em periódicos nacionais. 
http://dx.doi.org/10.5902/1984686X39764

\section{Método}

Este estudo é resultado de uma pesquisa bibliográfica. De acordo com Pizzani et al. (2012, p. 54), este tipo de investigação consiste em uma "revisão da literatura sobre as principais teorias que norteiam o trabalho científico. Essa revisão é o que chamamos de levantamento bibliográfico ou revisão bibliográfica". Cabe destacar ainda que "um trabalho de revisão crítica e de sistematização é essencial para dar um salto qualitativo nos referenciais teóricos" (OMOTE, 2014, p.13). A partir do levantamento bibliográfico, reflexões críticas podem ser realizadas sobre os avanços e a estagnação de uma temática dentro de determinada área de conhecimento.

O levantamento das publicações referentes às $A H$ na REE foi realizado em meio eletrônico, sendo coletados os dados em todas as edições disponibilizadas pelo site da própria $\mathrm{REE}^{2}$. Para a realização da busca, foram utilizadas, isoladamente, as seguintes palavras-chave: dotação, talento, precocidade, superdotação, criatividade, altas habilidades e superdotação, sendo um critério de inclusão o uso dessas palavras no título das produções.

O estudo foi dividido em etapas. A primeira etapa consistiu na divisão da quantidade de números da revista e no período das publicações entre as pesquisadoras, denominadas P1, P2, P3 (Quadro 1).

Quadro 1 - Primeira etapa - Divisão do número de revistas por pesquisadora (P1, P2, P3)

\begin{tabular}{|c|c|c|c|}
\hline & Ano/Edições & Ano/Edição & Total \\
\hline P1 & $\begin{array}{l}2000 / \text { n. } 15 \text { e } 16 ; 2001 / \text { n. } 17 \text { e } 18 ; 2002 / \text { n. } 19 \text { e } 20 ; \\
2003 / \text { n. } 21 \text { e } 22 ; 2004 / \text { n. } 23 \text { e } 24 ; 2005 / \text { n. } 25 \text { e } 26 ; \\
2006 / \text { n. } 27 \text { e } 28 ; 2007 / \text { n. } 29 \text { e } 30 .\end{array}$ & $\begin{array}{c}2014 / \text { n.50 } \\
04 \text { artigos }\end{array}$ & $\begin{array}{l}16 \text { números da revista } \\
+04 \text { artigos }\end{array}$ \\
\hline P2 & $\begin{array}{l}\text { 2008/ n. } 31 \text { e } 32 ; 2009 / \text { n. } 33,34 \text { e } 35 ; 2010 / \text { n. } 36,37 \\
\text { e } 38 ; 2011 / \text { n. } 39 / 40 / 41 ; 2012 / \text { n. } 42,43,44 ; 2013 / \text { n. } 45 \\
\text { e } 46\end{array}$ & $\begin{array}{c}2014 / \text { n. } 50 \\
04 \text { artigos }\end{array}$ & $\begin{array}{l}16 \text { números da revista } \\
+04 \text { artigos }\end{array}$ \\
\hline P3 & $\begin{array}{l}2013 / \text { n. } 47 ; 2014 / \text { n. } 48 \text { e } 49 ; 2015 / \text { n. } 51,52 \text { e } 53 ; 2016 / \\
\text { n. } 54,55 \text { e } 56 ; 2017 / \text { n. } 57,58 \text { e } 59 ; 2018 / \text { n. } 60,61,62 \\
\text { e } 63 .\end{array}$ & $\begin{array}{c}2014 / \mathrm{n} .50 \\
04 \text { artigos }\end{array}$ & $\begin{array}{l}16 \text { números da revista } \\
+04 \text { artigos }\end{array}$ \\
\hline
\end{tabular}

Fonte: Elaboração das autoras (2019). 
Na segunda etapa, houve a seleção dos artigos e recorreu-se à leitura exploratória dos resumos, das palavras-chave. Em seguida, realizou-se uma leitura crítica de todos os artigos selecionados. Durante esse processo, as produções científicas foram organizadas e sistematizadas com o auxílio da planilha Excel@, contendo as seguintes categorias em relação ao perfil das publicações: quantidade de artigos por ano de publicação, tipo de produção científica, autoria, vinculação institucional dos autores e temáticas abordadas nas produções.

Na terceira etapa, foram catalogados e selecionados apenas os artigos resultantes de pesquisa empírica sobre a identificação das $\mathrm{AH}$. Em seguida, foi realizada uma análise dos procedimentos e instrumentos de identificação. Para tanto, adotaram-se as seguintes categorias: tipo de produção científica, caracterização dos participantes, instrumentos utilizados na identificação, método, resultados.

Os dados coletados foram submetidos a uma análise quantitativa e qualitativa, tendo como base a análise de indicadores bibliométricos (HAYASHI, 2013) e a análise de conteúdo (BARDIN, 2016) das produções científicas que compuseram este corpus.

\section{Resultados e discussão}

\section{Indicadores bibliométricos da produção científica sobre AH na REE}

O levantamento realizado na REE resultou em um total de cinquenta e seis (56) produções acadêmicas sobre AH no período de 2000 a 2018. Desse total, foram encontrados cinquenta e cinco (55) artigos $^{3}$ - dois (02) deles traduções dos artigos publicados em língua inglesa e uma (1) resenha. Esse total de artigos representa 8,84\% das publicações da revista em comparação aos artigos publicados sobre outros temas da EE durante o período pesquisado.

Em relação à distribuição temporal das cinquenta e cinco (55) produções analisadas, os resultados indicaram um período de dezenove (19) anos (Gráfico 1), havendo uma concentração de 27,3\% ( $n=15)$ em 2014, ano em que a edição de número 50 da Revista apresentou um dossiê, intitulado Altas Habilidades/Superdotação: uma questão da Educação Especial. 
http://dx.doi.org/10.5902/1984686X39764

Gráfico 1 - Quantidade de produções científicas sobre altas habilidades por ano de publicação

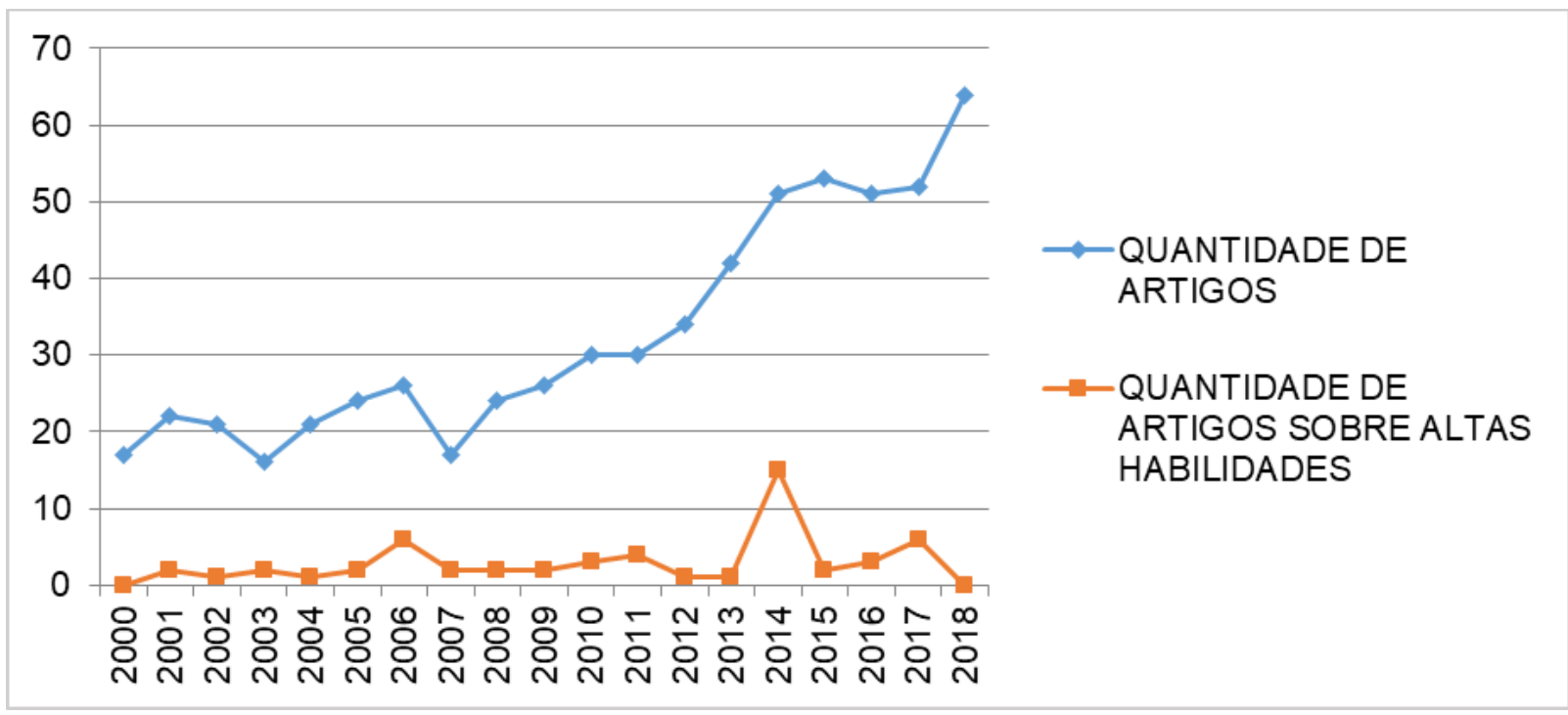

Fonte: Dados da pesquisa. Elaboração das autoras (2019).

Em 2006 e 2017, a produção atinge 10,9\% (n=6) em cada ano. Nos demais, a quantidade de artigos é inferior a 9,9\% (n=5). Além disso, nos anos 2000 e 2018, não houve publicação de artigos sobre a temática na REE. O Gráfico 1 esboça aumento nas produções sobre $\mathrm{AH}$ a partir de 2006, mesmo diante de uma pequena queda em 2007. Verifica-se, ainda assim, que o contingente de pesquisas sobre $\mathrm{AH}$ é pouco expressivo se comparado à produção de outros temas, como consta na pesquisa de Barbosa (2014).

$\mathrm{Na}$ análise comparativa, pode-se notar ainda que, conforme se verifica no Gráfico 1, houve aumento progressivo da quantidade de publicações da revista a partir de 2008; em contrapartida, exceto em 2014, a quantidade de artigos sobre AH permaneceu constante, sem alterações significativas no fluxo de publicações. Ademais, percebe-se também que, em 2018, ano em que a Revista publicou o maior número de artigos ( $n=64)$, a temática das AHnão foi contemplada em nenhuma edição.

Nesse sentido, vale ainda destacar que, levando-se em conta o número médio de artigos publicados na REE sobre a $\mathrm{AH}$ ao longo do período pesquisado ( $\mathrm{n}=2$ artigos), em comparação com os artigos publicados sobre outras temáticas da Educação Especial ( $n=32$ artigos), há uma diferença significativa que foi acentuando-se ao longo dos anos, especialmente a partir do ano 2008, indicando ainda o número exíguo de publicações sobre aárea das $\mathrm{AH}$ no periódico, corroborando a hipótese de que segundo a qual a produção científica sobre essa área, em todo território nacional, é escassa (FLEITH; ALENCAR, 2007; VIRGOLIM, 2007; FREITAS, 2014). 
http://dx.doi.org/10.5902/1984686X39764

Algumas argumentações tendem a corroborar e reforçar essa hipótese. Em primeiro lugar, Barbosa (2014), ao realizar uma revisão bibliográfica sobre essa temática entre 2009 e 2013, no banco de dados da Scientific Eletronic Library Online (SCIELO), notou que as produções dos artigos tinham momentos de crescimento e recuo. Porém, esse autor asseverou que é preciso cautela ao "propor hipóteses de crescimento, estabilidade ou diminuição dessas publicações ao longo do tempo", porque estão em jogo os critérios de periodização da revista, variáveis externas, como, por exemplo, as políticas públicasque corroboram as ações a respeito da temática, além dos temas de pesquisa explorados no contexto atual (BARBOSA, 2014, p. 118).

Em segundo lugar, Barbosa (2014) discute a fragilidade metodológica que pode interferir no impacto da pesquisa no meio científico, na comunidade escolar e na sociedade. O autor argumenta ainda a carência, em relação à área das AH no contexto brasileiro, de pesquisas mais sequenciais com expressividade na amostra e mais rigor no tratamento dos dados. Omote (2014), em consonância com esse posicionamento, acrescenta outros aspectos: a falta de interessepela área e o desconhecimento sobre a existência da temática.

Em terceiro lugar, deve-se ainda considerar a perpetuação dos mitos em torno das AH (ANTIPOFF; CAMPOS, 2010). Segundo Pérez (2012, p. 01), os mitos não só colaboram para uma escassez de estudos, como também, constituem um sério empecilho "para a formação de uma identidade própria das PAHs e contribuem para uma representação negativa ou, pelo menos, distorcida destas pessoas". Dessa maneira, corrobora para o desconhecimento dessa condição e, consequentemente, para a falta de identificação e atendimento a esse público-alvo da EE.

No que se refere aos tipos de produções científicas (Gráfico 2), constatou-se, no periódico, a predominância de ensaios teóricos, perfazendo $45,3 \%(n=24)$ ao longo do período pesquisado. Em seguida, os relatos de pesquisa, com $34 \%(n=18)$; depois as revisões de literatura, correspondendo um total de $18,9 \%(n=10)$ e, por sua vez, a resenha, com $1,9 \%$. 
http://dx.doi.org/10.5902/1984686X39764

Gráfico 2 - Tipos de produções científicas sobre altas habilidades

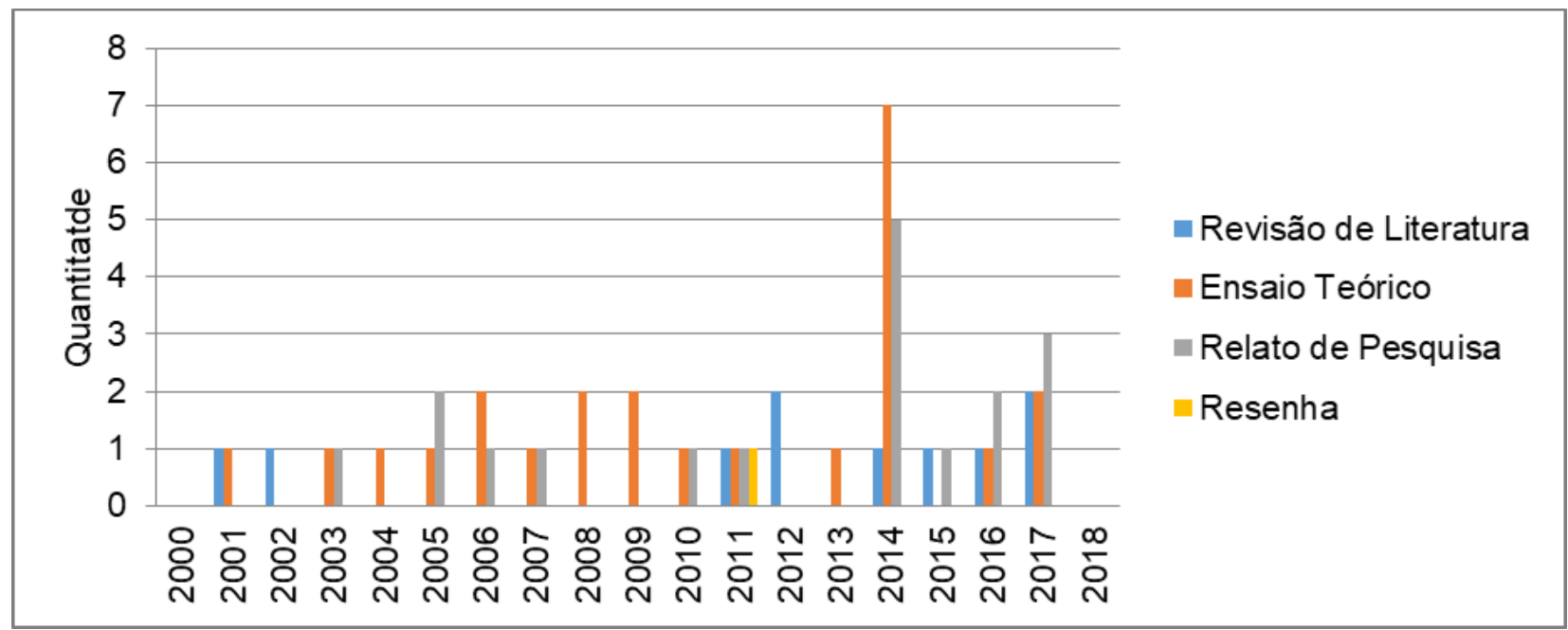

Fonte: Dados da pesquisa. Elaboração das autoras (2019).

Os resultados referentes ao tipo de produção científica divergem dos encontrados por Barbosa (2014), que identificou uma porcentagem maior de relatos de pesquisas empíricas do que de Revisões de Literatura e Ensaios Teóricos. A elevada porcentagem de artigos que podem ser classificados no grupo de ensaios teóricos deve ser avaliada com cautela. Embora sejam estudos científicos relevantes, sabe-se que contribuições para o avanço do conhecimento científico estão indubitavelmente atreladas à realização de pesquisas empíricas, como assinala esse autor. Constatou-se também, no Gráfico 2, que o percentual de relatos de pesquisas é inferior ao de ensaios teóricos. Esse dado pode indicar uma séria lacuna nos estudos sobre a $\mathrm{AH}$ no Brasil: a pouca realização de pesquisas empíricas com esse público.

Em relação à autoria dos artigos, percebeu-se que $62 \%$ das produções do periódico foram redigidas em coautoria (Gráfico 3). Nesse sentido, confirmou-se uma tendência das publicações no campo da Educação, o que tem sido avaliado como positivo, pois favorece a realização de intercâmbios com outros grupos de pesquisa e auxilia também no desenvolvimento de redes de colaboração científicas interdisciplinares (LOPES; COSTA, 2012). 
http://dx.doi.org/10.5902/1984686X39764

Gráfico 3 - Distribuição dos artigos por quantidade de autores

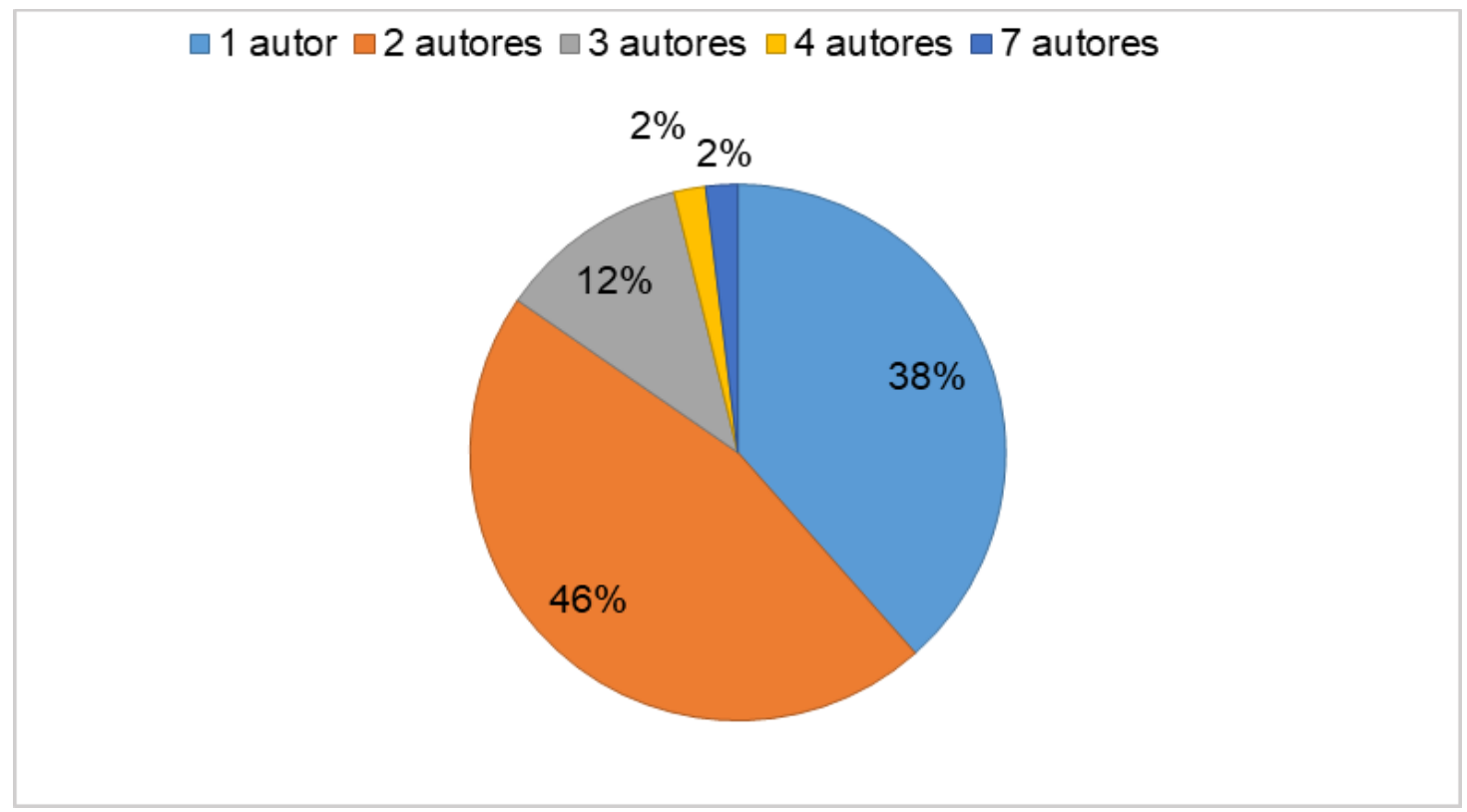

Fonte: Dados da pesquisa. Elaboração das autoras (2019).

Cabe ressaltar que, na área das $\mathrm{AH}$, esse tipo de colaboração científica pode ainda favorecer o desenvolvimento de pesquisas no futuro, fortalecendo os estudos sobre a área no Brasil, que, embora estejam aumentando o número de produções, ainda são considerados escassos é considerado escasso (FLEITH; ALENCAR, 2007; FREITAS, 2014).

A vinculação institucional dos autores (Gráfico 4) indica que a maior contribuição para a área provém de universidades públicas $(n=16)$, seguidas das instituições particulares $(n=$ 6) e das estrangeiras $(n=3)$ respectivamente. Essas dezesseis instituições públicas brasileiras estão distribuídas nas regiões sudeste $(n=6)$, sul $(n=4)$, centro-oeste $(n=4)$, norte e nordeste $(n=1)$ cada uma. Entre as instituições particulares, a região sudeste também se destaca $(n=4)$, seguidas das regiões sul $(n=2)$ e centro-oeste $(n=1)$.

Além dessas instituições, houve contribuições de pesquisadores de Organizações Não-Governamentais, como o Conselho Brasileiro para Superdotação (ConBrasd), a Associação Gaúcha de Apoio às Altas Habilidades/Superdotação (AGAAHSD) e o Centro para o Desenvolvimento do Potencial e Talento (CEDET), entre outras (Gráfico 4). 
http://dx.doi.org/10.5902/1984686X39764

Gráfico 4 - Vinculação institucional dos autores por quantidade de publicações

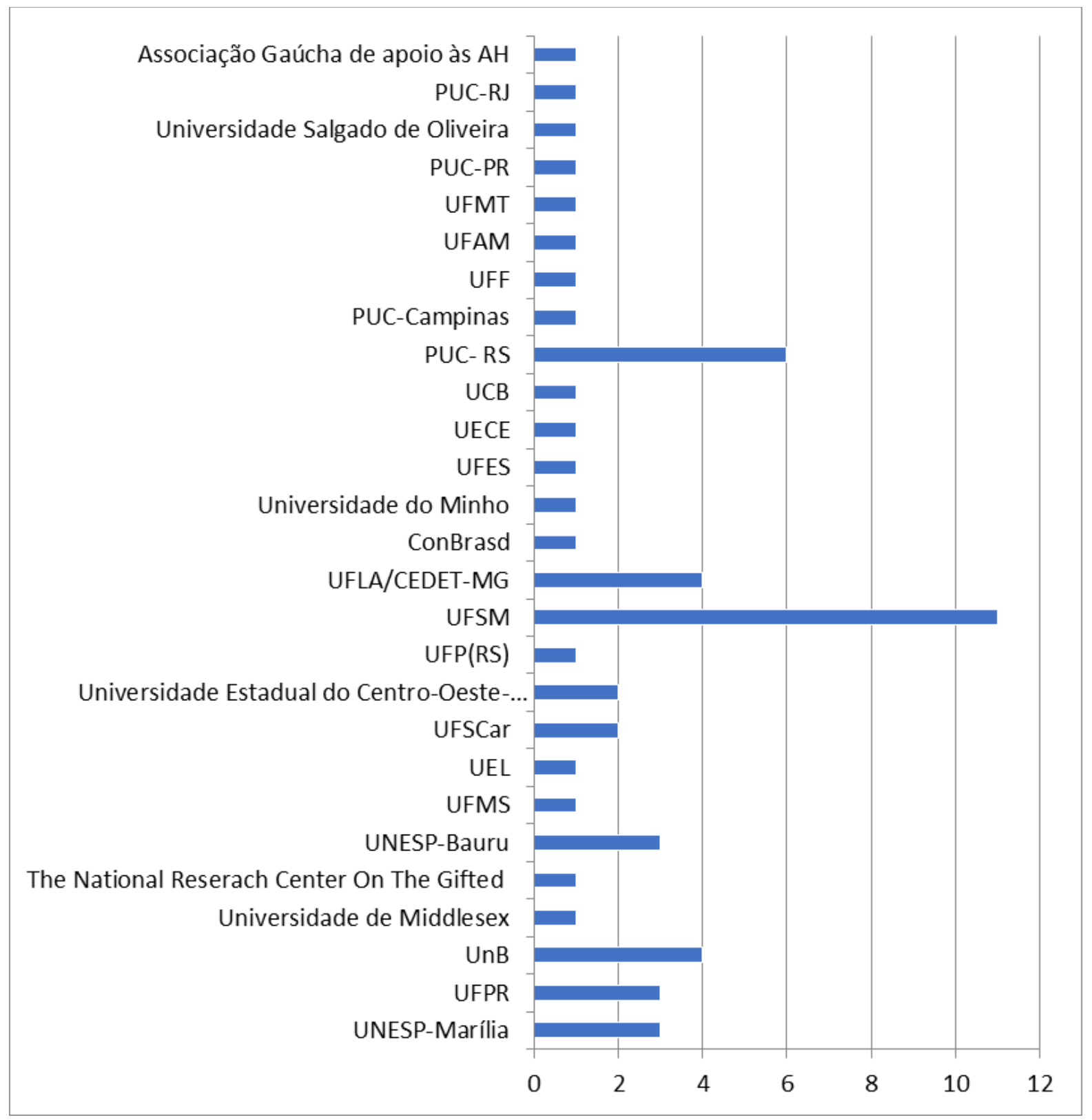

Fonte: Dados da pesquisa. Elaboração das autoras (2019).

Dessa maneira, verifica-se que há mais instituições públicas e particulares da região sudeste pesquisando sobre as $\mathrm{AH}$. Em contrapartida, as instituições da região sul apresentam maior quantidade de produções no periódico $(n=23)$ do que a região sudeste $(n=17)$. Cabe ressaltar que as regiões norte e nordeste apresentam o menor número de produções no periódico, o que pode indicar o pouco interesse pela área ou ainda o pouco envolvimento de pesquisadores com esse campo de conhecimento nessas regiões.

No que diz respeito às temáticas abordadas nos artigos (Gráfico 5), confirmaram-se os resultados de outras revisões (FREITAS; ROSDA; COSTA, 2014; PEDRO et al., 2016), 
em que a identificação de $\mathrm{PAH}$ tem sido a temática mais investigada da área. Na REE, ao longo dos dezenove (19) anos pesquisados, o tema da identificação foi abordado em 22,6\% de todas as produções referentes à área. Em seguida, a temática da inclusão escolar foi objeto de estudo em $20,8 \%$ das produções, depois, a caracterização da produção científica $(11,3 \%)$, desenvolvimento socioemocional $(9,4 \%)$, programas de atendimento $(7,5 \%)$, inclusão social $(3,7 \%)$ e os demais temas $(1,9 \%)$.

Gráfico 5 - Temáticas abordadas nos artigos publicados na REE

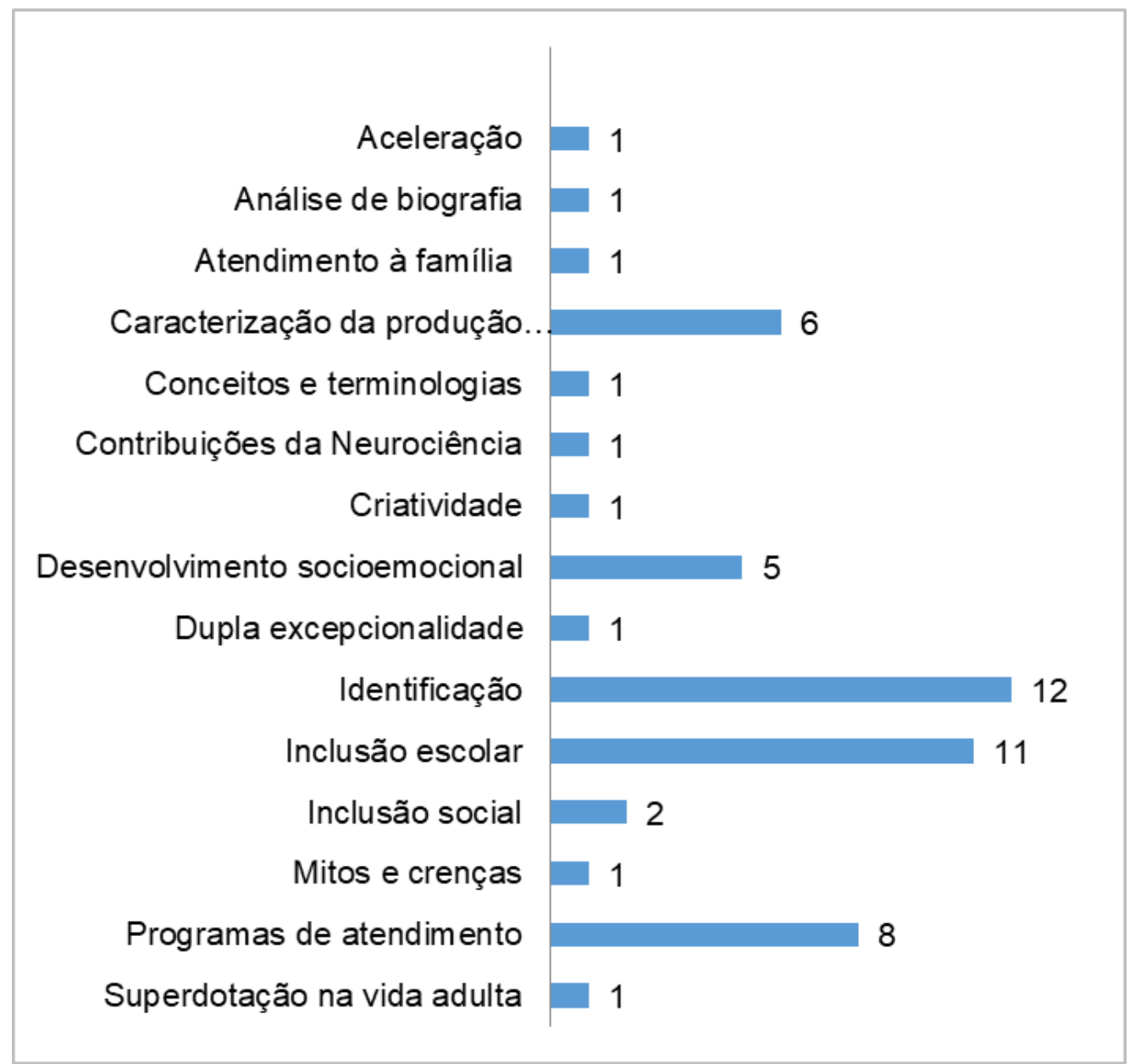

Fonte: Dados da pesquisa. Elaboração das autoras (2019).

Alguns temas da área, como aceleração, atendimento à família, que estão diretamente relacionados com os tipos de apoio/serviço que devem ser ofertados ao estudante, no ambiente escolar, e à família, tem recebido pouca atenção dos pesquisadores, representando uma significativa lacuna nos estudos da área no Brasil.

Nesse sentido, esse baixo número de pesquisas sobre a aceleração no periódico pode ser interpretado como um indicativo da subnotificação desse público na escola brasileira, revelado pela análise do número de matrículas divulgado nos censos escolares (FARIAS; 
WECHSLER, 2014). Outro aspecto que pode também corroborar essa situação é o pouco entendimento sobre as múltiplas modalidades de aceleração que podem ser praticadas no âmbito escolar. Conforme advertem Freeman e Guenther (2000), no Brasil, por conta da Lei de Diretrizes e Bases da Educação Nacional (LDBEN), convencionou-se interpretar por aceleração a passagem do estudante mais capaz para séries acima de sua faixa etária, saltando séries escolares ou parte delas. No entanto, a aceleração, segundo as autoras, também deve ser compreendida como a oferta de provisão individualizada que possibilite ao estudante realizar, de modo mais rápido, seu próprio aprendizado (FREEMAN; GUENTHER, 2000).

Em relação ao atendimento às famílias, deve-se ainda destacar que o modo como os pais percebem as $\mathrm{AH}$ interfere diretamente na maneira de lidar com os filhos, sendo, portanto, necessários suportes/serviços de apoio que possam disseminar informações sobre a área às famílias. Vários autores (SABATELLA, 2007; SAKAGUTI, BOLSANELLO, 2012; DELOU, 2007) salientam, inclusive, a importância de a família construir conhecimentos sobre a área para auxiliar no desenvolvimento socioeducacional de crianças e adolescentes com $\mathrm{AH}$.

No tocante à escassez de produções, ainda foi possível verificar que, entre outros temas, o da dupla excepcionalidade, ao longo dos 19 anos, foi objeto de estudo em apenas uma ( $n=1)$ publicação na revista, confirmando a análise realizada por Ourofino (2007). Segundo essa autora, a dupla excepcionalidade, no contexto brasileiro, constitui um tema emergente que vem surpreendendo, inclusive, pesquisadores experientes. Além de ser um tema emergente, convém assinalar que ele ainda resulta em confusão e crítica, especialmente fora da área da educação de estudantes com $\mathrm{AH}$, pois, de acordo com Reis, Baum e Burke (2014), ainda há profissionais que consideram os termos deficiência e $\mathrm{AH}$ incompatíveis e esse aspecto pode corroborar para o baixo número de estudos em torno dessa temática.

\section{Investigações empíricas sobre a identificação de pessoas com altas habilidades}

No total, foram encontrados doze (12) artigos sobre a temática da identificação ao longo do período pesquisado. Desse total, 66,7\% $(n=8)$ foram estudos empíricos em comparação com os estudos teóricos $(n=4)$, que perfazem $33,3 \%$ das produções sobre a identificação de AH.No Quadro 2, pode-se visualizar uma síntese das investigações empíricas sobre a identificação das AH publicadas na REE, no período de 2000 a 2018. 
http://dx.doi.org/10.5902/1984686X39764

Quadro 2 - Estudos empíricos sobre a identificação de pessoas com altas habilidades

\begin{tabular}{|c|c|c|c|c|}
\hline & Referência & Participantes & Método & Instrumentos \\
\hline 1 & $\begin{array}{l}\text { Oliveira; } \\
\text { Anache } \\
(2006)\end{array}$ & $\begin{array}{l}\text { Dois profissionais } \\
\text { responsáveis pelo } \\
\text { núcleo de inclusão da } \\
\text { rede Estadual. }\end{array}$ & Qualitativo & 1.Documentos; 2. Entrevista. \\
\hline 2 & $\begin{array}{l}\text { Guenther } \\
\text { (2006) }\end{array}$ & $\begin{array}{l}5000 \text { crianças } \\
\text { observadas por ano (de } \\
1992 \text { a 1996) }\end{array}$ & $\begin{array}{l}\text { Qualitativo/ } \\
\text { Quantitativo }\end{array}$ & 1. Ficha de observação direta \\
\hline 3 & $\begin{array}{l}\text { Fortes; } \\
\text { Freitas } \\
\text { (2007) }\end{array}$ & $\begin{array}{l}\text { Ausência de descrição } \\
\text { dos participantes do } \\
\text { estudo. }\end{array}$ & Quantitativo & $\begin{array}{l}\text { 1. Instrumento de autoria de Zenita Guenther } \\
\text { (2000) (não foi especificado qual instrumento } \\
\text { foi utilizado); } 2 \text {. Entrevista semiestruturada } \\
\text { para professores; } 3 \text {. Avaliação pedagógica. }\end{array}$ \\
\hline 4 & $\begin{array}{l}\text { Pérez } \\
\text { (2009) }\end{array}$ & $\begin{array}{l}38 \text { estudantes. Gênero } \\
\text { feminino }(n=11) \text { e } \\
\text { masculino }(n=27) \text {, com } \\
\text { idades entre } 8 \text { anos e } 2 \\
\text { meses e } 18 \text { anos. } \\
05 \text { adultos }- \text { Gênero } \\
\text { feminino }(n=4) \quad \text { e } \\
\text { masculino }(n=1) .\end{array}$ & Quantitativo & $\begin{array}{l}\text { 1. Três questionários PAH/SD de diferentes } \\
\text { faixas etárias (crianças de } 6 \text { a } 9 \text { anos; } \\
\text { crianças e adolescentes) } \\
\text { de } 10 \text { a } 18 \text { anos e adultos; } \\
\text { 2. Um questionário de Autonomeação; } \\
\text { 3. Um questionário de Nomeação } \\
\text { (instrumentos de triagem); } \\
\text { 4. Uma ficha Complementar de } \\
\text { Características Artísticas e Esportivas } \\
\text { (FCCAE). }\end{array}$ \\
\hline 5 & $\begin{array}{l}\text { Simonetti; } \\
\text { Almeida; } \\
\text { Gunther } \\
\text { (2010) }\end{array}$ & $\begin{array}{l}93 \text { estudantes } \\
\text { indicados por seus } \\
\text { professores, dos quais } \\
77 \text { foram submetidos à } \\
\text { avaliação psicométrica } \\
\text { (utilização da escala } \\
\text { de inteligência WISC-III). }\end{array}$ & Quantitativo & $\begin{array}{l}\text { 1. Roteiro para registro dos dados pelos } \\
\text { professores observadores; } \\
\text { 2. Teste para a avaliação da capacidade } \\
\text { intelectual- WISC-III; } \\
\text { 3. Eletroencefalograma quantitativo / } \\
\text { mapeamento cerebral - O EEGQ } \\
\text { 4. Fichas para anamnese familiar e escolar. }\end{array}$ \\
\hline 6 & $\begin{array}{l}\text { Veiga } \\
(2014)\end{array}$ & $\begin{array}{l}28 \text { alunos com idades de } \\
8 \text { a } 17 \text { anos. }\end{array}$ & $\begin{array}{l}\text { Quantitativo/ } \\
\text { Qualitativo }\end{array}$ & $\begin{array}{l}\text { 1. Entrevista evolutiva modular; } 2 . \\
\text { Questionário para pais; 3. Brasão familiar; } 4 . \\
\text { E.M.C.A.; 5. WISC III; 6. Provas multimodais; } \\
\text { 7. Provas cognitivas modulares; }\end{array}$ \\
\hline 7 & $\begin{array}{l}\text { Koga; } \\
\text { Chacón } \\
\text { (2017) }\end{array}$ & $\begin{array}{l}17 \text { estudantes da } \\
\text { Educação. Infantil e dos } \\
\text { Ensinos Fundamental I e } \\
\text { II/ Gênero feminino }(n=7) \\
\text { e masculino }(n=10) .\end{array}$ & Quantitativo & $\begin{array}{l}\text { Testes psicométricos de aptidão musical } \\
\text { (PMMA e o IMMA). }\end{array}$ \\
\hline 8 & $\begin{array}{l}\text { Mendonça, } \\
\text { Rodrigues, } \\
\text { Capellini } \\
(2017)\end{array}$ & $\begin{array}{l}15 \text { professores e } 267^{*} \\
\text { estudantes do Ensino } \\
\text { Fundamental I. } \\
\text { Gênero feminino: } \\
(n=127) \text { e masculino } \\
(n=140) \\
\text { ldade: } 06 \text { a } 13 \text { anos. } \\
\text { *Só } 259 \text { participaram de } \\
\text { todas as etapas. }\end{array}$ & $\begin{array}{l}\text { Quantitativo/ } \\
\text { Qualitativo }\end{array}$ & $\begin{array}{l}\text { Testes das Matrizes Progressivas de Raven; } \\
\text { Teste de desempenho escolar (TDE) e } \\
\text { Escala de indicadores de AH/SD para } \\
\text { professores, elaborada por Guenther. }\end{array}$ \\
\hline
\end{tabular}

Fonte: Dados da pesquisa. Elaboração das autoras (2019).

Oliveira e Anache (2006) pesquisaram a identificação e o encaminhamento de alunos com $\mathrm{AH}$ em Campo Grande/MS. As autoras caracterizaram a pesquisa como sendo de cunho exploratório. O objetivo do estudo foi analisar o panorama do processo de 
http://dx.doi.org/10.5902/1984686X39764

identificação e encaminhamento em Campo Grande e como os resultados eram tratados pelos órgãos competentes dedicados ao encaminhamento dos estudantes identificados. Para isso, os instrumentos utilizados foram: entrevistas e documentos. O locus da pesquisa concentrou-se na rede estadual de ensino e no núcleo de inclusão da rede. Os resultados foram organizados nas seguintes categorias: conceito de inteligência, conceito de superdotado, processo de identificação e procedimento de encaminhamento. As autoras chegaram à conclusão de que os critérios de identificação ainda são empecilhos no rastreio da PAH e a abordagem psicométrica ainda pesa na elaboração do diagnóstico.

Guenther (2006) criou um procedimento para a identificação e reconhecimento da dotação e talento. Para tanto, estabeleceu critérios que indicassem o fenômeno de modo relativamente estável e mensurável. Além disso, a autora focalizou a trajetória da identificação como um processo fluido e sequencial, mas sem apresentar um crivo como os dos testes padronizados. Seu instrumento é composto por questionários, entrevistas, checklists, indicações por parte dos pais, professores e colegas e observação direta e/ou identificação por observação em sala de aula ${ }^{4}$. Guenther (2006) criou uma listagem de características com traços e atributos gerais como forma de sondagem dos domínios de capacidade natural e expressão de talentos específicos a serem observados pelos professores. Para encontrar a validade do instrumento, utilizou a análise tri-fatorial ${ }^{5}$. Com relação a esse estudo, é preciso destacar a ausência dos detalhes sobre o procedimento de validação e os números dos resultados da análise tri-fatorial que permitiriam ao leitor averiguar se os itens de fato conseguem estabelecer parâmetros de medida para aquilo que foram criados. A pesquisa foi desenvolvida durante os anos de 1992 a 1996, com um expressivo número de participantes - 5000 crianças. Vale salientar que esse número expressivo e representativo de participantes cumpriria exigências suficientes para uma pesquisa destinada à validação dos instrumentos.

Fortes e Freitas (2007) também apresentam o processo de identificação e encaminhamento de crianças com $\mathrm{AH}$ ao descreverem o Programa de Incentivo ao Talento $(\mathrm{PIT})^{6}$. As autoras realizaram o procedimento de identificação, por meio de método qualitativo, junto às escolas da rede pública municipal, estadual e particular da cidade de Santa Maria - RS. Elas mencionam que os instrumentos utilizados, naquela ocasião, foram: um questionário com 26 itens de autoria de Guenther (2000), entrevista semiestruturada com professores e avaliação pedagógica. Não houve especificação ou descrição dos procedimentos utilizados na análise dos dados, corroborando para dificultar a validação da 
http://dx.doi.org/10.5902/1984686X39764

identificação realizada no estudo. As autoras relataram ainda que é necessária a articulação entre todos os envolvidos no processo de inclusão de pessoas com $\mathrm{AH}$.

Pérez (2009), em seu estudo, teve como objetivo central apresentar os questionários para a identificação de alunos com AH sob uma perspectiva multidimensional, baseados em Renzulli e colaboradores, os quais são aplicados aos professores, alunos e responsáveis, sendo seis (06) instrumentos: três (03) para serem respondidos por pessoas com $\mathrm{AH}$ de diferentes faixas etárias (crianças de 6 a 9 anos; crianças e adolescentes de 10 a 18 anos e adultos), dois (02) para o cruzamento de informações de crianças e adolescentes (respondidos por responsáveis e professores) e uma (1) Ficha para Características Artísticas e Esportivas, para os alunos que manifestam destaque em alguma dessas áreas. Como instrumentos complementares, foram apresentados Questionário de Autonomeação e Nomeação pelos Colegas e Ficha Complementar de Características Artísticas e Esportivas (FCCAE). Pérez afirma que os instrumentos foram aplicados para validação a 38 alunos (11 meninas e 27 meninos) identificados com AH e que eles podem ser complementados por outras medidas avaliativas. A autora também expôs os Questionários para Identificação de Indicadores de Altas Habilidades - Aluno e Adultos, validados em estudo piloto realizado com cinco (05) participantes, na faixa etária de 22 a 57 anos, realizados com quatro (04) mulheres e um (01) homem.

Simonetti, Almeida e Guenther (2010) investigaram o efeito da realização de tarefas cognitivas verbais e espaciais no comportamento de sujeitos dotados, utilizando o sinal psicofisiológico, a atividade cerebral por meio de técnica obtida por eletroencefalograma quantitativo com mapeamento cerebral (EEGQ). Além desse recurso instrumental, os pesquisadores aplicaram o teste WISC III aos 77 participantes do estudo (estudantes de 11 a 13 anos). Os resultados identificaram 15 estudantes - sete $(n=7)$ meninos e oito $(n=8)$ meninas - com AH. Os autores chegaram à conclusão de que existe uma aproximação entre os resultados da avaliação psicométrica e os indicadores psicofisiológicos para a identificação de PAH.

Veiga (2014) apresenta as etapas de identificação e avaliação de PAH. Sua pesquisa vincula-se ao Núcleo de Prática em Psicologia da PUC/PR e as 28 crianças avaliadas foram aquelas, cujos pais buscaram ajuda do Núcleo com a finalidade de obtenção de um diagnóstico. Para o procedimento de identificação, Veiga (2014) utilizou uma entrevista evolutiva modelar, um questionário para pais, o teste Brasão Familiar, Entrevista Modelar Centrada na Aprendizagem, o teste WISC III e as provas multimodais e cognitivas 
http://dx.doi.org/10.5902/1984686X39764

modulares. A análise quali-quantitativa dos dados considerou medidas obtidas nos testes padronizados e os dados obtidos com a realização da entrevista e dos questionários. A autora chegou à conclusão de que as concepções da Psicopedagogia Modular, assim como alguns instrumentos, são eficazes na identificação de PAH.

Koga e Chacón (2017) expõem o processo de identificação e enriquecimento do talento musical desenvolvidos no Programa de Atenção a Alunos Precoces com Comportamento de Superdotação (PAPCS). Nesse estudo, por meio de método quantitativo, os autores aplicaram dois testes psicométricos (PMMA, IMMA)para avaliação da acuidade auditiva em dezessete $(n=17)$ crianças, sendo sete $(n=7)$ meninas e dez $(n=10)$ meninos, identificadas como precoces com comportamento de superdotação. Os resultados do estudo apontaram que 58,82\% $(n=10)$ dos estudantes apresentaram acuidade auditiva elevada, confirmando indicadores de precocidade e comportamento de superdotação musical. Os autores salientaram que todas as dezessete $(n=17)$ participaram do Programa de Enriquecimento Musical, confirmando, desse modo, coerência com a teoria adotada na pesquisa, a qual se baseou nas propostas de Joseph Renzulli $(1990 ; 2005)$.

A pesquisa realizada por Mendonça, Rodrigues e Capellini (2017) teve como objetivo central realizar uma identificação das $\mathrm{AH}$, nas áreas intelectual e acadêmica, em estudantes do Ensino Fundamental. As autoras propuseram uma identificação inicial, de modo a realizar uma triagem, por meio de três instrumentos: Teste das Matrizes Progressivas Coloridas de Raven, Teste de Desempenho Escolar (TDE) e Questionário de Indicação de Professores. Participaram do estudo duzentos e sessenta e sete $(n=267)$ crianças, sendo cento e vinte e sete $(n=127)$ meninas e cento e quarenta $(n=140)$ meninos. Os resultados indicaram oitenta e um $(n=81)$ alunos com indicativos de $\mathrm{AH}$. Na comparação dos três instrumentos, as autoras salientaram que houve diferenças significativas na identificação dos estudantes, demonstrando pouca concordância entre eles. No entanto, como se trata de uma identificação inicial a ser prosseguida por meio de uma avaliação mais detalhada, a pouca ou a ausência de compatibilidade entre os achados nos três instrumentos pode ser interpretada como positiva, já que isso sugere maior quantitativo de estudantes a serem considerados para a continuação do processo de identificação.

\section{Análise das investigações e recomendações para futuras pesquisas}

Ao longo dos dezenove $(n=19)$ anos, a REE divulgou oito $(n=8)$ estudos empíricos sobre a identificação de pessoas com $A H$. Desses estudos, quatro $(n=4)$ deles não fizeram 
http://dx.doi.org/10.5902/1984686X39764

descrição dos participantes da pesquisa, cinco $(n=5)$ não expõem características de gênero, três $(n=3)$ não esclarecem a idade dos participantes da pesquisa e quatro $(n=4)$ não sinalizam o nível de ensino quando se referem aos estudantes. Também não há indicações do perfil profissional dos participantes, quando envolveu professores e outros profissionais. Além disso, observou-se que, em alguns estudos, não houve uma descrição detalhada dos instrumentos e dos procedimentos utilizados na coleta e análise dos dados.

Percebe-se, desse modo, fragilidades metodológicas como assevera Omote (2014) em relação à produção acadêmica na área da Educação Especial. Esse tipo de fragilidade reverbera, de modo negativo, na produção de conhecimento sobre a área das $\mathrm{AH}$. Conforme afirma Barbosa (2014, p. 116), as evidências produzidas sobre as AH não têm sido suficientes para "propiciar uma base científica sólida para os processos de identificação de estudantes com talento e para a formulação de programas capazes de atender suas necessidades educacionais". Essa fragilidade metodológica impede que o fenômeno seja minimamente compreendido e que políticas públicas sejam pensadas e até mesmo reformuladas para melhor atender ao público em questão.

No que se refere aos métodos de pesquisa utilizados nas investigações, representados no quadro 2, observa-se que houve predominância do método quantitativo $(n=4)$, seguido de estudos que utilizaram método misto $(n=3)$ e depois o método qualitativo $(n=1)$. Nota-se, dessa maneira, que vários métodos têm sido utilizados na investigação para a identificação das $\mathrm{AH}$. Se, por um lado, isso pode indicar dificuldades na comparação dos resultados entre os estudos, processo que é reforçado pela variedade e quantidade de instrumentos utilizados em cada investigação; por outro, esse dado pode indicar também que a pesquisa sobre a identificação das $\mathrm{AH}$ tem caminhado para a adoção da tese da unidade dos paradigmas quantitativo e qualitativo - (SANTOS FILHO, 2013), objetivando a compreensão desse tema complexo na área das AH. De acordo com Santos Filho (2013, p. 49), "os métodos quantitativo e qualitativo não são incompatíveis; pelo contrário, estão intimamente imbricados e, portanto, podem ser usados pelos pesquisadores sem caírem em contradição epistemológica".

Dessa forma, para a realização de pesquisas nessa área, visando à superação do "estágio adolescente" (SANTOS FILHO, 2013, p. 51), da pesquisa nas Ciências Humanas e da Educação, recomenda-se o reconhecimento e a adoção da ideia segundo a qual o avanço do conhecimento relaciona-se com a articulação e a complementaridade dos paradigmas. 
http://dx.doi.org/10.5902/1984686X39764

Além dessa recomendação, vale salientar que a identificação das pessoas com $\mathrm{AH}$ tem sido a temática mais pesquisada entre os estudiosos da área. Por essa razão, as pesquisas analisadas apontam para a necessidade de que futuras investigações empíricas sobre esse tema possam indicar claramente os participantes do estudo, com critérios de inclusão e exclusão bem definidos, com descrição detalhada do delineamento metodológico, além de uma caracterização dos instrumentos utilizados, a fim de que possam ser replicados, corroborando, para que, no futuro, os educadores e profissionais da área possam contar com uma evidência científica mais segura acerca da validade do delineamento e dos instrumentos empregados na identificação das $\mathrm{AH}$.

Sabe-se que o tipo de evidência científica construída pode dar uma contribuição importante à melhoria do atual estado das políticas públicas e das práticas educativas em torno da identificação dos estudantes com AH no âmbito das escolas brasileiras, revertendo, possivelmente, o quadro da subnotificação no censo escolar brasileiro (FARIAS; WECHSLER, 2014). Deve-se ainda considerar que a inclusão de fato desses estudantes perpassa pela identificação, pelo registro nos censos escolares que, indubitavelmente, servem como parâmetro para a elaboração de políticas públicas direcionadas a esse público da EE (PÉREZ; FREITAS, 2014).

Além disso, convém destacar que os resultados desta revisão parecem indicar que, ao longo desses 19 anos, poucos foram os estudos sobre outras temáticas da área, tais como: aceleração, precocidade, atendimento à família, dupla excepcionalidade, desenvolvimento socioemocional da $\mathrm{PAH}$, as $\mathrm{AH}$ na fase adulta, constituindo lacunas a serem consideradas em futuras proposições de pesquisas, conforme também salientaram Pedro et al. (2016).

\section{Considerações finais}

De um modo geral, os resultados indicaram, ao longo dos dezenove anos $(n=19)$, poucas publicações sobre as $\mathrm{AH}$ na REE. Além disso, há um número escasso de estudos empíricos, indicando baixas proposições de pesquisas envolvendo as PAH. Notou-se ainda que algumas temáticas, como aceleração, precocidade, dupla excepcionalidade, atendimento à família, entre outras, têm sido pouco exploradas pelos estudiosos da área, dada as poucas e esparsas produções ao longo do período pesquisado.

As produções sobre a identificação das $\mathrm{PAH}$, além de utilizarem procedimentos e instrumentos diversificados - o que dificulta a comparação e a replicação dos estudos e, por consequência, a avaliação da validade dos procedimentos e instrumentos adotados para a 
identificação da PAH, também revelaram fragilidades metodológicas, indicando lacunas na seleção, caracterização dos participantes das pesquisas, descrição dos instrumentos de coleta e procedimentos de análise dos dados.

Sugere-se, desse modo, que, além da descrição detalhada dos procedimentos e instrumentos metodológicos sobre a identificação da $\mathrm{PAH}$, a adoção e criação de instrumentos educacionais validados, com constructos teóricos e metodológicos coerentes e condizentes com a realidade educacional brasileira. Desse modo, defende-se também que os instrumentos de avaliação, especialmente os empregados por educadores, possam ser replicados, visando ao estabelecimento de sua fidedignidade.

Para tanto, sabe-se que é necessário investir na formação inicial e continuada de professores, pois estudos com rigor científico e divulgação de seus resultados nos cursos de licenciatura e pedagogia podem contribuir para amenizar a subnotificação de matrículas desses estudantes nos censos escolares e a escassez da produção científica e das propostas de atendimento para esse público no cenário da educação brasileira.

\section{Referências}

ALENCAR, Eunice Maria Lima Soriano. Psicologia e educação do superdotado. São Paulo: EPU, 1986, p. 97.

ALENCAR, Eunice Maria Lima Soriano; FLEITH, Denise Souza. Superdotados: determinantes, educação e ajustamento. 2.ed. São Paulo: EPU, 2001, p. 188.

ANTIPOFF, Cecília Andrade; CAMPOS, Regina Helena de Freitas. Superdotação e seus mitos. Revista Semestral da Associação Brasileira de Psicologia Escolar e Educacional, São Paulo, p. 301-309,v. 14, n. 2, jul/dez.,2010. Disponível em:

http://www.scielo.br/pdf/pee/v14n2/a12v14n2. Acesso em: 04 ago. 2019.

BARBOSA, Altemir José Gonçalves. O método das pesquisas sobre talento: análise a partir de artigos indexados na base de dados Scielo. In: OMOTE, Sadao.; OLIVEIRA, Anna Augusta Sampaio; CHACON, Miguel. Ciência e conhecimento em Educação Especial. São Carlos: Marquezine e Manzini, 2014, p. 115-124.

BARDIN, Lawrence. Análise de conteúdo. Tradução de Luís Antero Reto e Augusto Pinheiro. São Paulo: Edições 70, 2016, p. 279.

BRASIL. Ministério da Educação. Decreto 7.611/2011. Dispõe sobre a educação especial, o atendimento educacional especializado e dá outras providências. Diário Oficial da União, Brasília: DF, 17 nov. 2011. Disponível em:

http://www.prograd.ufu.br/sites/prograd.ufu.br/files/media/documento/8.6__decreto_ndeg_7.611-11___acessib.pdf. Acesso em: 01 ago. 2018. 
BRASIL. NAAH/S: documento orientador. Brasília: MEC/SEESP, 2006. Disponível em: http://portal.mec.gov.br/seesp/arquivos/doc/documento\%20orientador_naahs_29_05_06.doc. Acesso em: 26 jun. 2018.

BRASIL. Nota Técnica n. 04. MEC/SECADI/DPEE. Orientação quanto a documentos comprobatórios de alunos com deficiência, transtornos globais do desenvolvimento e altas habilidades/superdotação no Censo Escolar, 2014. Disponível em:

http://portal.mec.gov.br/index.php?option=com_docman\&view=download\&alias=15898nott04-secadi-dpee-23012014\&category_slug=julho-2014-pdf\&Itemid=30192. Acesso em: 10 jul. 2019.

BRASIL. Ministério da Educação. Política Nacional de Educação Especial na Perspectiva da Educação Inclusiva, Brasília. DF, 07 jan. 2008. Disponível em: http://portal.mec.gov.br/arquivos/pdf/politicaeducespecial.pdf. Acesso em: 05 maio 2018.

BROWN, Scott W. et al. Assumptions Underlying the Identification of Gifted and Talented Students. Gifted Child Quarterly, v. 49, n. 1, p. 68-79, 2005. Disponível em: http://scihub.tw/https://doi.org/10.1177\%2F001698620504900107. Acesso em 22 jun. 2019.

DELOU, Cristina Maria Carvalho. O papel da família no desenvolvimento de altas habilidades e talentos. In: FLEITH, Denise de Souza; ALENCAR, Eunice M. L. Soriano.

Desenvolvimento de talentos e altas habilidades: orientação a pais e professores. Porto Alegre: Artmed, 2007, p.131-141.

FARIAS, Eliana Santos; WECHSLER, Solange Muglia. Desafios na identificação de alunos intelectualmente dotados. In: VIRGOLIM, A. M. R.; KONKIEWITZ, E. C. (Org.). Altas habilidades/superdotação, inteligência e criatividade. Campinas, SP: Papirus, 2014, p. 335-350.

FLEITH, Denise Souza; ALENCAR, Eunice Maria Lima Soriano. Apresentação. In: FLEITH, Denise Souza; ALENCAR, Eunice Maria Lima Soriano (Org.). Desenvolvimento de talentos e altas habilidades: orientação a pais e professores. Porto Alegre: Artmed, 2007, p. 9-22.

FORTES, Caroline Corrêa; FREITAS, Soraia Napoleão. PIT - Programa de Incentivo ao Talento: um relato das experiências pedagógicas realizadas com alunos com características de altas habilidades. Revista Educação Especial, Santa Maria, nov. 2011. ISSN 1984-686X. Disponível em: https://periodicos.ufsm.br/educacaoespecial/article/view/4181. Acesso em: 15 maio 2019.

FREEMAN, Joan; GUENTHER, Zenita C. Educando os mais capazes: ideias e ações comprovadas. São Paulo: EPU, 2000, p. 183.

FREITAS, Soraia Napoleão. Altas habilidades/superdotação em pesquisa: um olhar dirigido. In: OMOTE, Sadao; OLIVEIRA, Anna Augusta. Sampaio; CHACON, Miguel. Ciência e conhecimento em Educação Especial. São Carlos: Marquezine e Manzini, 2014, p. 125134. 
FREITAS, Soraia Napoleão; HOSDA, Carla Beatriz Kunzler; COSTA, Leandra Costa da. A produção científica em altas habilidades/superdotação nas revistas brasileiras de Educação Especial. Revista Diálogos e Perspectivas em Educação Especial. v. 1, n.1, p. 75-84, Jun.-Dez., 2014. Disponível em:

http://revistas.marilia.unesp.br/index.php/dialogoseperspectivas/issue/view/281. Acesso em 12 jun. 2019.

GAMA, Maria Clara Sodré Salgado. Educação de superdotados: teoria e prática. São Paulo: EPU, 2006, p. 175.

GARDNER, Howard. Estruturas da mente: a teoria das inteligências múltiplas. Trad. Sandra Costa. Porto Alegre: Artes Médicas, 1994, p. 340.

GARDNER, Howard. Inteligência: um conceito reformulado. Trad. Adalgisa Campos da Silva. Rio de Janeiro: Objetiva, 2001, p. 347.

GUENTHER, Zenita Cunha. Dotação e talento: reconhecimento e identificação. Revista Educação Especial, Santa Maria, p. 195-208, nov. 2006. ISSN 1984-686X. Disponível em: https://periodicos.ufsm.br/educacaoespecial/article/view/4281. Acesso em: 15 maio 2019.

HAYASHI, Carlos. Roberto Massao. Apontamentos sobre a coleta de dados em estudos bibliométricos e cientométricos. Filosofia e Educação, Campinas, SP, v. 5, n. 2, p. p. 89-102, 2013. ISSN 1984-9605. Disponível em:

https://periodicos.sbu.unicamp.br/ojs/index.php/rfe/article/view/8635396. Acesso em: 28 jul. 2018.

KOGA, Fabiana Oliveira; CHACON, Miguel Claudio Moriel. Programa de atenção a alunos precoces com comportamento de superdotação: identificação e proposta de enriquecimento musical. Revista Educação Especial, Santa Maria, p. 83-102, abr. 2017. ISSN 1984-686X. Disponível em: https://periodicos.ufsm.br/educacaoespecial/article/view/18972. Acesso em: 15 maio 2019.

LINS, Manuela Ramos Caldas; BORSA, Juliane Callegaro. Prefácio. In: LINS, Manuela Ramos Caldas; BORSA, Juliane Callegaro (Orgs.). Avaliação psicológica: aspectos teóricos e práticos. Petrópolis, RJ: Vozes, 2017, p. 9-22.

LOPES, Alice Casimiro; COSTA, Hugo Heleno Camilo. A produção bibliográfica em coautoria na área de educação. Rev. Bras. Educ., Rio de Janeiro, v. 17, n. 51, p. 717-730, 2012.

Disponível em: http://www.scielo.br/scielo.php?script=sci arttext\&pid=S1413$24782012000300013 \&$ Ing=en\&nrm=iso . Acesso em 01 ago. 2018.

MACHADO, Járci Maria; STOLTZ, Tânia. Da identificação à intervenção nas AH/SD: uma trajetória e muitos desafios. In: PISKE, Fernanda Hellen Ribeiro et al. (Orgs.). Altas habilidades/superdotação (AH/SD) e criatividade: identificação e atendimento. Curitiba: Juruá, 2016, p. 261-276.

MARCUSCHI, Luíz Antônio. Da fala para a escrita: atividades de retextualização. 2. ed. São Paulo: Cortez, 2001, p.133. 
MENDONÇA, Lurian Dionizio; RODRIGUES, Olga Maria Piazentin Rolim; CAPELLINI, Vera Lúcia Messias Fialho. Identificação inicial de alunos com altas habilidades ou superdotação: avaliação intelectual, de desempenho escolar e indicação pelos professores. Revista Educação Especial, Santa Maria, p. 203-218, abr. 2017. ISSN 1984-686X. Disponível em: https://periodicos.ufsm.br/educacaoespecial/article/view/24120. Acesso em: 15 maio 2019.

OLIVEIRA, Cynthia Garcia; ANACHE, Alexandra Ayach. A identificação e o encaminhamento dos alunos com Altas Habilidades / Superdotação em Campo Grande - MS. Revista Educação Especial, Santa Maria, p. 61-84, nov. 2006. ISSN 1984-686X. Disponível em: https://periodicos.ufsm.br/educacaoespecial/article/view/4348. Acesso em: 15 maio 2019.

OMOTE, Sadao. Produção acadêmica em Educação Especial. In: OMOTE, Sadao; OLIVEIRA, Anna Augusta Sampaio; CHACON, Miguel Claudio Moriel (Org.). Ciência e conhecimento em Educação Especial. São Carlos: Marquezine\& Manzini: ABPEE, 2014, p. 13-23.

OUROFINO, Vanessa Tentes Alves. Altas habilidades e hiperatividade: a dupla excepcionalidade. In: FLEITH, Denise Souza; ALENCAR, Eunice Maria Lima Soriano. Desenvolvimento de talentos e altas habilidades: orientação a pais e professores. Porto Alegre: Artmed, 2007, p. 51-66.

PASQUALI, Luiz. Psicometria: teoria dos testes na psicologia e na educação. 5. ed. Petropólis, RJ: Vozes, 2013, p. 399.

PEDRO, Ketiling Mayra; OGEDA, Clarissa Maria Marques; MORAES, Lucas Almeida Prado de. CHACON, Miguel Claudio Moriel. Altas habilidades ou superdotação: levantamento dos artigos indexados no SciELO. Interfaces da Educ., Paranaíba, v.7, n.19, p.275-295, 2016. Disponível em: https://periodicosonline.uems.br/index.php/interfaces/article/view/1039/964. Acesso em: 22 jun. 2019.

PÉREZ, Susana Graciela Pérez Barrera. Mitos e Crenças sobre as Pessoas com Altas Habilidades: alguns aspectos que dificultam o seu atendimento. Revista Educação Especial, Santa Maria, p. 45-59, mar. 2012. ISSN 1984-686X. Disponível em: https://periodicos.ufsm.br/educacaoespecial/article/view/5004/3033. Acesso em: 19 ago. 2019.

PÉREZ, Susana Graciela Pérez Barrera; FREITAS, Soraia Napoleão. Políticas públicas para as Altas Habilidades/Superdotação: incluir ainda é preciso. Revista Educação Especial, Santa Maria, p. 627-640, set. 2014. ISSN 1984-686X. Disponível em: https://periodicos.ufsm.br/educacaoespecial/article/view/14274. Acesso em: 15 maio 2019.

PISKE, Fernanda Hellen Ribeiro. Alunos com altas habilidades/superdotação (AH/SD): como identificá-los? In: PISKE, Fernanda Hellen Ribeiro et al. (Org.). Altas habilidades/superdotação (AH/SD) e criatividade: identificação e atendimento. Curitiba: Juruá, 2016, p.249-276.

PIZZANI, Luciana.; SILVA, Rosemary Cristina; BELLO, Suzelei Faria.; HAYASHI, Maria Cristina Piumbato Innocentini. A arte da pesquisa bibliográfica na busca do conhecimento. RDBCl: Revista Digital de Biblioteconomia e Ciência da Informação, v. 
http://dx.doi.org/10.5902/1984686X39764

10, n. 2, p. 53-66, 10 jul. 2012. Disponível em:

https://periodicos.sbu.unicamp.br/ojs/index.php/rdbci/article/view/1896. Acesso em: 18 jun. 2020.

REIS, Sally. M.; BAUM, Susan. M.; BURKE, Edith. An Operational Definition of TwiceExceptional Learners: Implications and Applications. Gifted Child Quarterly, v. 58, n. 3, 2014, p. 217-

230.Disponívelem:http://journals.sagepub.com.ez31.periodicos.capes.gov.br/doi/pdf/10.1177/ 0016986214534976 . Acesso em: 15 abr. 2018.

RENZULLI, Joseph S. The Three-Ring conception of giftedness: a developmental model for promoting creative productivity. IN: STERNBERG, Robert Jeffrey; DAVIDSON, Janet E.

(Orgs.). Conceptions of giftedness. 2.ed. New York: Cambridge University Press, 2005, p. 246-279.

RENZULLI, Joseph S. A practical system for identifying gifted and talented students, Early Child Development and Care,v. 63, n. 1, p. 9-18, 1990. Disponível em:

https://doi.org/10.1080/0300443900630103. Acesso em 10 abr. 2019.

SABATELLA, Maria Lúcia Prado. Atendimento às famílias de alunos com altas habilidades. In:FLEITH, Denise de Souza; ALENCAR, Eunice Maria Lima Soriano (Orgs.).

Desenvolvimento de talentos e altas habilidades: orientação a pais e professores. Porto Alegre: Artmed, 2007, p. 143-150.

SAKAGUTI, Paulo MitsuyoYamasaki; BOLSANELLO, Maria Augusta. A família e o aluno com altas habilidades/superdotação. In: MOREIRA, Laura Ceretta; STOLTZ, Tania (Org.). Altas habilidades/superdotação, talento, dotação e educação. Curitiba: Juruá, 2012, p. 221 235.

SANTOS FILHO, José Camilo dos. Pesquisa quantitativa versus pesquisa qualitativa: o desafio paradigmático. In: SANTOS FILHO, José Camilo dos; GAMBOA, Silvio Sánchez (org.). Pesquisa educacional: quantidade-qualidade. 8. ed. São Paulo: Cortez, 2013, p. 1358.

SIMONETTI, Dora Cortat; ALMEIDA, Leandro S.; GUENTHER, Zenita. Identificação de alunos com altas capacidades: uma contribuição de indicadores neuropsicológicos. Revista Educação Especial, Santa Maria, jun. 2010. ISSN 1984-686X. Disponível em: https://periodicos.ufsm.br/educacaoespecial/article/view/1633. Acesso em: 15 maio 2019.

STERNBERG, Robert Jeffrey; DAVIDSON, Janet E. Conceptions of giftedness. 2.ed. New York: Cambridge University Press, 2005, p. 467.

STERNBERG, Robert. Jeffrey. The Theory of Successful Intelligence. Gifted Education International, v. 15, n.1, p. 4-21, 2000. Disponível em: http://scihub.tw/https://doi.org/10.1177\%2F026142940001500103. Acesso em: 22 jun. 2019.

TREFFINGER, Donald J.; RENZULLI, Joseph S. Giftedness as potential for creative productivity: transceding IQ scores, Roeper Review, v. 8, n. 3, p. 150-154, 1986. Disponível em: 
http://dx.doi.org/10.5902/1984686X39764

https://www.researchgate.net/publication/247528034_Giftedness_as_potential_for_creative_p roductivity_Transcending_IQ_scores/link/5a1f4326a6fdccc6b7fb25ef/download. Acesso em: 10 abr. 2019.

VEIGA, Elizabeth Carvalho da. Altas Habilidades/Superdotação e a psicopedagogia modular: avaliando potencialidades. Revista Educação Especial, Santa Maria, p. 641-648, set. 2014. ISSN 1984-686X. Disponível em:

https://periodicos.ufsm.br/educacaoespecial/article/view/14283. Acesso em: 15 maio 2019.

VIRGOLIM, Angela Mágda Rodrigues. Altas habilidades e desenvolvimento intelectual. In: In: FLEITH, Denise Souza; ALENCAR, Eunice Maria Lima Soriano (Orgs.). Desenvolvimento de talentos e altas habilidades: orientação a pais e professores. Porto Alegre: Artmed, 2007, p. 25-40.

VIRGOLIM, Angela Mágda Rodrigues. Identificação de alunos com altas habilidades/superdotação no contexto brasileiro: sugestões do modelo de enriquecimento escolar de J. Renzulli. In: PISKE, Fernanda Hellen Ribeiro et al. (Orgs.). Altas habilidades/superdotação (AH/SD) e criatividade: identificação e atendimento. Curitiba: Juruá, 2016, p. 219-247.

\section{Notas}

${ }^{1}$ Nesse período, o periódico se chamava "Cadernos de Educação Especial” e foi um dos primeiros, no Brasil, dedicados às temáticas da Educação Especial.

${ }^{2}$ Podem ser encontradas as edições da REE desde 0 ano 2000 no site https://periodicos.ufsm.br/educacaoespecial.

${ }^{3}$ Em relação à quantidade de produções acadêmicas, foram contabilizadas as traduções dos artigos como publicações científicas, considerando que receberam espaço próprio no periódico. Como elas, no entanto, não podem ser consideradas gêneros textuais (MARCUSCHI, 2001), não foram selecionadas no escopo das demais categorias de análise.

${ }^{4}$ Esse procedimento foi utilizado no Centro para o Desenvolvimento do Potencial e Talento (CEDET). É preciso destacar que a autora é afundadora do CEDET e criadora da metodologia para identificação e atendimento no Modelo proposto por François Gagné.

${ }^{5} \mathrm{~A}$ autora afirma que a validação científica foi encontrada, uma vez que o processo de identificação do CEDET atinge diferentes populações em distintas classes sociais e que houve significativosavanços na identificação e no atendimento.

${ }^{6}$ Programa ancorado na Universidade Federal de Santa Maria, RS.

\section{Correspondência}

Josilene Domingues Santos Pereira - Instituto Federal de Educação, Ciência e Tecnologia da Bahia (IFBA) - Av. Sérgio Vieira de Mello, 3150 - Zabelê, Vitória da Conquista, Bahia - Brasil.

CEP: $45078-300$

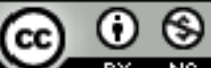

4.0 International (CC BY-NC 4.0) 